\title{
THE DEVELOPMENT OF ENERGY INNOVATION IN THE FIELD OF DECARBONIZATION OF THE ECONOMY: ANALYSIS OF INDICATORS
}

\section{Olena Trofymenko ${ }^{1}$}

DOI: https://doi.org/10.30525/978-9934-26-076-6-30

The energy industry plays an important role in socio-economic development of the country. Nowadays, the majority of developed countries are working on a fundamentally new ideology of how the energy sector should be constructed and how it must operate in order to supply consumers with safe, reliable, cost-effective, and environmentally friendly energy. Active informatization and intellectualization of energy facilities, innovation processes form the basis of this ideology. Fossil fuels combustion satisfies about $80 \%$ of world energy needs; however, its emissions are considered one of the major causes of global warming. Therefore, the introduction of innovative energy technologies is one of the primary goals in the development of the energy sector at the global level, as it will help to improve energy efficiency, cut pollution and reduce the negative impact on the environment.

Since anthropogenic emissions of greenhouse gases into the atmosphere are a big reason behind global climate change, it is vital for countries of the world to switch to a low-carbon economy. This process is called global decarbonisation and it aims to reduce harmful emissions in order to stop climate change and minimize its damage. The UN Summit on Sustainable Development approved twelve Global Sustainable Development Goals by 2030, one of which is Goal 7 "Affordable and Clean Energy». This goal can be achieved by 2030 if the following tasks are carried out - promoting R\&D activities in the energy industry, increasing the share of renewable energy in

\footnotetext{
${ }^{1}$ International University of Finance, Ukraine
} 
the global energy balance, decarbonisation of the economy, the introduction of energy innovation.

The ranking of countries according to the Global Energy Innovation Index National Contributions to the Global Clean Energy Innovation System from the organization ITIF [1, p. 4] is analysed. Based on the ranking, a list of leading countries in terms of the introduction of innovative technologies in the energy industry is compiled. Overall, the functional components of the indicators show the main existing trends in the development of innovation in the energy sector, because they include specific areas for investment. 23 countries that make substantial contributions to clean energy innovation are used to calculate the ITIF Global Energy Innovation Index. Norway, Finland, Japan, the United States and France have the highest indicators of innovation.

While GDP growth is an essential indicator of efficiency of the national economy, the reduction in the energy intensity of GDP is one of the indicators of energy efficiency of the national economy. Thus, the reduction in the energy intensity requires the introduction of innovative technologies into energy production. There is no doubt that this will have a good influence on the environment in the direction of decarbonisation. Consequently, 23 countries are graphically depicted with the values of the Global Index of Energy Innovation (the diameter of the circle) in the coordinates of the indices Fossil $\mathrm{CO}_{2}$ per capita (tons of $\mathrm{CO}_{2}$ per capita) [2] and GDP per capita. Since the study of the Global Index of Energy Innovation was conducted in 2019, the data for this year are used.

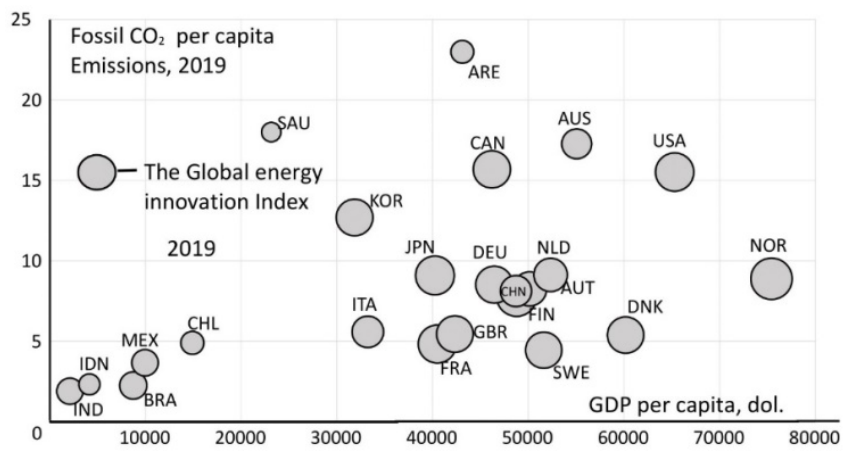

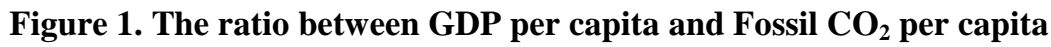
(ton emission) in terms of The Global energy innovation index

Source: [3, p. 4] 
Fossil $\mathrm{CO}_{2}$ per capita is an indicator of carbon dioxide emissions resulting from burning fossil fuels and cement production and of carbon dioxide formed during the consumption of solid, liquid and gaseous fuels and gas combustion. It is logical to assume that the introduction of alternative and innovative technologies for energy production should cut such emissions. The graph illustrates that Saudi Arabia and the United Arab Emirates are the countries that use traditional fuels a lot; therefore, they have a higher level of Fossil $\mathrm{CO}_{2}$ per capita and a relatively low index of energy innovation. It is observed that the greater the value of GDP, the much higher the rate of $\mathrm{CO}_{2}$ emissions, so it is necessary to compare these indicators of developed countries, because such a comparison will provide opportunities to increase the ratio of GDP to $\mathrm{CO}_{2}$ emissions.

Norway is considered the leading country in terms of the implementation of energy innovation, as it has an overall estimate of the index of 15.5, GDP per capita of 75419.63 dollars and a relatively low Fossil $\mathrm{CO}_{2}$ per capita of 8.89 tonnes. Finland, which has the value of 14.8, GDP per capita of 48782.8 dollars and Fossil $\mathrm{CO}_{2}$ per capita of 7.81 tonnes, takes second place by an overall estimate of the index. Japan is third in the list with an overall estimate of the index of 13.7; it has lower GDP of 40246.9 dollars and slightly higher Fossil CO2 per capita of 9.09 tonne emissions.

Overall, the positions of the countries in these coordinates do not show a directly proportional relationship between GDP and Fossil $\mathrm{CO}_{2}$ per capita, and the Global Energy Innovation Index. Only some countries on the list indicate this relationship, such as Norway, Denmark, the Netherlands, and China. Despite that, it is clear that high-tech countries have a high index of energy innovation. For instance, Finland, France, Japan, Germany, Canada, and the United Kingdom whose GDP ranges from 40,000 to 55,000 invest in the development and spread of energy efficient technologies. Finland's GDP per capita is 33\% lower than that of the United States, but in terms of energy innovation, Finland introduces 10\% more energy innovation than the United States does. Another point to mention is that the US, Austria and Canada have relatively high $\mathrm{CO}_{2}$ emissions, although the GDP of the US is higher than that of Canada, which testifies to the fact that the USA production is more ecofriendly. This means that high-tech countries, irrespective of their GDP, are engaged in investing in energy efficiency and «clean» energy projects, which will cut energy consumption and harmful emissions.

The introduction and development of renewable energy, which belongs to the innovative areas of the energy industry is one of the essential directions of decarbonisation of the economy. Nowadays the United States, China, Germany, Brazil, India, and the United Kingdom are the leading countries in renewable energy consumption. 
The global investment in energy efficiency technology fell sharply in 2019 compared to 2016 [4]. Meanwhile, global investment in renewable energy sources has been rising steadily. Consequently, the development of renewable energy sources in the world is a high priority.

The dynamics of Renewable Consumption in Ukraine and in the world as a whole characterize the stages of the development of renewable energy consumption in the world in relation to Ukraine. The consumption of renewable energy for the period from 1998 to 2019 was studied. By 2007, the world consumption of renewable energy was gradually growing. From 2007 to 2009, Ukraine experienced a $44 \%$ decrease in renewable energy consumption but global consumption continued to rise. The use of renewable energy sources in Ukraine declined due to an economic crisis of 2008-2009 as well as a political crisis of 2008-2009. For the period of 3 years, from 2009 to 2011, renewable energy consumption was steadily increasing. From 2011 to 2014, the use of renewable energy in Ukraine rose by more than 7 times from 0.05 million toe to 0.41 million toe, while the world consumption of renewable energy gradually increased - from 265.6 thousand toe up to 382.8 thousand toe. From 2014 to 2016, the use of renewable energy sources in Ukraine fell again owing to the political and economic situation in 2014. Furthermore, in 2014, Ukraine suffered the consequences of a political crisis, military aggression in the east, and the annexation of the Crimea by the Russian Federation [3].

These events triggered inflation, a 6.8\%fall in real GDP, which, of course, adversely affected the development of renewable energy production. From 2016 to 2019, there was a significant rise in renewable energy consumption to 1.11 million toe. The Association Agreement with the EU helped the process of renewable energy development since the agreement requires that Ukraine implement reforms in the energy industry using innovative environmental technologies and renewable energy. Additionally, Ukraine approved the New Energy Strategy until 2035, which defines renewable energy capacity as one of the priorities. After analysing all the data, it possible to conclude that despite global crises, the consumption of renewable energy in the world is growing, while the crisis in Ukraine hinders the development of renewable energy in Ukraine.

Today it is important to study the main measures of the countries with a high index of global energy innovation and of the leading countries with a developed energy policy so that Ukraine can use their experience in achieving Sustainable Development Goals 7 and 12. It can be stated that the results of the study are establishing the relationship existing among $\mathrm{CO}_{2}$ emissions reduction, finding the resulting indicators of innovation in the energy sector and the economy based on the analysis of them in different countries. 


\section{References:}

1. Cunliff C., Hart D. M. (2019, August 26). The Global Energy Innovation Index: National Contributions to the Global Clean Energy Innovation System. URL: https://itif.org/publications/2019/08/26/global-energy-innovation-index-nationalcontributions-global-clean-energy

2. Fossil $\mathrm{CO}_{2}$ and GHG emissions of all world countries, 2019 report. EDGAR. (2019). URL:https://edgar.jrc.ec.europa.eu/overview.php?v=booklet2019

3. Voitko S., Trofymenko O., Pavlenco T. (2021) Decarbonisation of the economy through the introduction of innovative technologies into the energy sector. E3S Web of Conferences, 255, 01016. doi:10.1051/e3sconf/202125501016

4. World Energy Investment 2020 - Analysis. IEA. (2020, October 23). URL: https://www.iea.org/reports/world-energy-investment-2020 